\title{
On the Viability of Conditional Assistance Programs
}

Wolfgang Mayer and Alex Mourmouras 


\title{
IMF Working Paper
}

\author{
IMF Institute
}

\section{On the Viability of Conditional Assistance Programs}

\author{
Prepared by Wolfgang Mayer and Alex Mourmouras ${ }^{1}$ \\ Authorized for distribution by Eric V. Clifton
}

June 2005

\begin{abstract}
This Working Paper should not be reported as representing the views of the IMF. The views expressed in this Working Paper are those of the author(s) and do not necessarily represent those of the IMF or IMF policy. Working Papers describe research in progress by the author(s) and are published to elicit comments and to further debate.

Economic adjustment and reform programs, including those supported by international financial institutions (IFIs), must cope with informational asymmetries and special interest politics. This presents a particularly serious issue when IFIs make structural economic reforms a condition for providing economic assistance. This paper examines what conditions must be satisfied to make conditional assistance programs viable; that is, to ensure that the assistance-receiving government not only takes the assistance but also implements reforms, without compromising the country's political stability and the IFI's financial integrity. It is pointed out that tightly budgeted conditional assistance programs never bring about reforms, that the IFI's cost of viable programs rises with the dependence of the government on domestic interest groups, and that unconditional assistance might be viable when conditional assistance is not.

JEL Classification Numbers: E61; F33; F34

Keywords: IMF; economic reforms; conditionality; viability; incentive compatibility

Author(s) E-Mail Address: mayerw@uc.edu; amourmouras@imf.org

\footnotetext{
${ }^{1}$ Wolfgang Mayer is Professor of Economics and Chairman, Department of Economics, University of Cincinnati, Cincinnati, Ohio. Alex Mourmouras is Deputy Chief, European Division, IMF Institute. This paper was presented at the conference "Globalization: Prospects and Problems" in honor of Jagdish Bhagwati's 70th Birthday, University of Florida, Gainesville, January 28-30, 2005. For useful comments and suggestions we thank Elias Dinopoulos, Burkhard Drees, Andrew Feltenstein, Felix Hardy, Cem Karayalcin, Catherine Mann, Miguel Messmacher, Devashish Mitra and T.N. Srinivasan.
} 


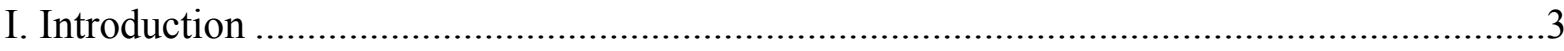

II. The Political Economy of the Assistance-Receiving Country .......................................6

III. The Interest Group as an Obstacle to Economic Reforms ..........................................8

IV. Viability of Conditional Assistance Programs ........................................................... 10

V. A Likely Scenario for Program Failure........................................................................ 13

VI. The Government's Dependence on Interest Groups and Conditional Loan Viability .......15

VII. Is Unconditional Assistance an Alternative?...........................................................17

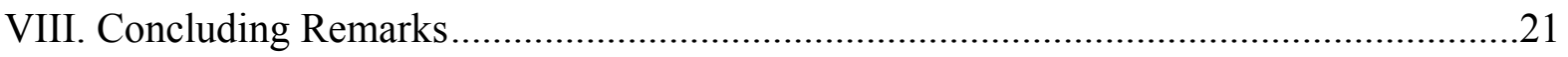

Figures

1. Conditional Versus Unconditional Assistance Choices..........................................26

2. Repayment Constraint Set With Unconditional Assistance.....................................27

Appendices

1. Constraint Set With Conditional Assistance .......................................................24

2. Constraint Set With Unconditional Assistance......................................................25

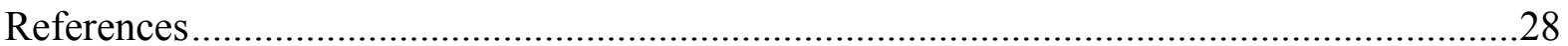




\section{INTRODUCTION}

The International Monetary Fund (IMF) and other international financial institutions (IFIs) provide financial, analytical, and technical assistance to member countries that face serious macroeconomic and structural problems. When such serious imbalances threaten a country, its government approaches (or is approached by) an IFI to negotiate an agreement that specifies conditions under which assistance may be made available. An important component of such conditional assistance programs is the requirement to implement structural reforms. The government of the assistance-receiving country is asked to reduce or eliminate distortions created by government policies and to adopt reform measures that will lead to a more efficient allocation of resources and to more rapid economic growth. ${ }^{2}$ What distinguishes such structural reforms from other (macroeconomic) stabilization and reforms is that it is far more difficult to monitor them, that they have a long gestation period, and that political-economy elements play an important role (Mussa and Savastano, 1999; p. 23).

This paper examines the viability of IFI-supported assistance programs that call for structural economic reform as a condition for receiving assistance. ${ }^{3}$ It does so by highlighting the implications of the "difficult to monitor" and "political-economy" features of structural reforms in a formal model in the tradition of transaction costs politics (Dixit, 2001, 2000). We describe a scenario in which an assistance-receiving government chooses policies under the influence of interest groups and the assistance-providing IFI is unable to observe the actual implementation of structural reforms. The paper's goal is to establish necessary conditions for the viability of a conditional assistance program; that is, to state conditions that must be met for the government not only to accept an IFI-designed assistance program but also to undertake the called-for reforms, and to do so without endangering the political stability of the assistance-receiving country and the financial stability of the assistanceproviding IFI. If any one of these conditions is violated, the program is not viable. ${ }^{4}$ The paper

\footnotetext{
${ }^{2}$ Mussa and Savastano (1999, p. 19), in discussing the IMF's approach to economic stabilization, refer to the securing of sustainable external financing, the adoption of demandrestraining measures, and the implementation of structural reforms as the main prongs of the stabilization approach. They add that conditionality of structural reforms has become an increasingly important component of assistance programs, especially when designed by IFIs other than the IMF (p. 23).

${ }^{3}$ There has been a great deal of criticism of IFI-designed conditional assistance programs, especially when they have a strong structural reform component. Most prominent among the themes of criticism is that of a lack of "ownership" of reforms. As Mussa and Savastano $(1999$, p. 7) state, .. "IMF programs tend to perform best when their associated policies are most closely "owned" by the national authorities in charge of implementing them." Ownership of reform policies, as the key to successful implementation of IFI-supported reforms, is also highlighted in the IMF's conditionality guidelines (IMF, 2002a). See also IMF (2001) and Boughton and Mourmouras (2004).

${ }^{4}$ Program viability is related to, but not the same as, the empirically tested "success" of conditional assistance programs. Dollar and Svensson (2000) consider a program to be a
} 
also examines unconditional assistance as an alternative to conditional assistance, especially when the latter is not viable.

As mentioned, structural reforms are difficult to monitor. The IFI is frequently unable to observe the actual implementation and enforcement of reforms as distinct from the rather easily observable passage of reform laws and regulations. This inability to observe the implementation of structural reforms results in a moral hazard issue associated with conditional assistance programs: there is asymmetric information between the assistancereceiving government and the assistance-providing IFI concerning the implementation of the reforms that form the core of the assistance agreement. ${ }^{5}$ Unless the agreement itself creates incentives for reform, the government will only take the offered assistance but not change its distorting economic policies.

The government's policy choice is motivated by political considerations. ${ }^{6}$ The government's goal is to maximize its overall political support, which stems from special interest groups ${ }^{7}$ and the general public. ${ }^{8}$ Economic policies that distort the economy are typically chosen to placate special interests, even if they hurt the general public. A viable conditional assistance program must take into account the political influence of interest groups. Specifically, the program that spells out the amount of the loan, its repayment conditions, and the type of reforms to be undertaken must be sufficiently attractive for the government to sacrifice some or all of the interest groups' political support.

success or failure based on the assessment of the Operations Evaluation Department of the World Bank. The department makes an overall judgment of whether the larger objectives of the reform have been attained. Hence, its focus is on whether reforms have been implemented. What impact the program has on the financial stability of the IFI is not evaluated.

${ }^{5}$ Some authors addressing information asymmetries in international markets have emphasized the screening and signaling role of IFIs (Marchesi and Thomas, 1999; Tirole, 2002; and IMF, 2004b).

${ }^{6}$ Dollar and Svensson (2000) find that political economy variables have a strong influence on the success rate of conditional assistance programs. A similar conclusion is drawn by Ivanova et. al. (2003).

${ }^{7}$ One of the pioneers of studying the influence of interest groups on a country's welfare is Bhagwati (1980, 1982). Interest groups engage in "directly-unproductive profit-seeking (DUP) activities" that lower welfare for the entire economy. The welfare consequences of these lobbying activities are further explored in Bhagwati and Srinivasan (1982).

${ }^{8}$ Drazen (2002) and Mayer and Mourmouras (2005) have modeled the relationship between an IFI and an interest group-influenced government in perfect symmetric information settings. 
A viable conditional assistance program requires the government not only to accept and implement the program, but to do so without endangering domestic political stability and without compromising the IFI's capacity to assist in the future. This paper models a world in which a country's production is stochastic. The economy might perform well or poorly independent of the country's resource base. The economy's actual performance depends on its initial resource base, the amount of assistance received to expand this base, the choice of economic policies, and unobservable stochastic production shocks. No matter how the economy performs, the general public is particularly sensitive to how externally dictated policies influence the outcome. A country's political stability becomes threatened when the public associates underperformance of the economy with intervention by the IFI; that is, when the public forms the belief that it would have been better off without IFI assistance and without reforms than with assistance and with reforms. To avoid the threat of political instability, the program's repayment conditions must be sufficiently flexible, meaning that they must be more lenient during bad times than during good times. Furthermore, the repayment conditions must be sufficiently generous in both good and bad times so the public always perceives acceptance of the conditional assistance package as being worthwhile for the country. ${ }^{9}$

Finally, IFIs are legally obligated to maintain the financial resources entrusted to them. Their charters contain the obligation to lend under adequate safeguards. This means that the repayment conditions of each conditional assistance program must be such that, ex ante, the IFI expects at least to break even. Ex post, the IFI gains from some programs and loses from others. But if production shocks are independently distributed among its large group of borrowers, the IFI's financial stability is secured if expected repayment of the loan is sufficiently large to cover the initial outlay.

This paper derives the viability conditions for conditional assistance in a simple model with one assistance-providing IFI, one assistance-accepting foreign government, and one interest group that tries to influence the government's policies. ${ }^{10}$ Given the economy's resources, its stochastic performance is limited to "good" and "bad." The probability of the performance being good, in turn, depends on whether the economy operates under policy distortions or is reformed. Assistance adds to the economy's resource base. How "good" and how "bad" is the performance of the economy performs is influenced by the amount of assistance received.

\footnotetext{
${ }^{9}$ In reality, IFIs provide various relief measures to countries hit by bad economic conditions, including debt relief and roll-overs of liabilities to future periods. While they are usually negotiated ex post, assistance-receiving governments are aware of the availability of such relief measures at the time they sign the agreement. Hence, the availability of such measures has the same effect as a priori specified flexible repayment conditions.

${ }^{10}$ If there was more than one interest group, the increased number of groups would have a moderating influence on policy distortions provided these groups have competing interests. To show this explicitly requires the formulation of a multi-sector economy and the discussion of what policy instrument raises a given group's welfare. This considerable complication would add little to enhance our understanding of the viability of conditional assistance programs.
} 
The paper provides three basic insights. The first one pertains to conditional assistance programs that are just barely attractive enough for a government to join the IFI at the negotiating table. An IFI, in an attempt to assist more countries, might approach governments and offer conditional assistance. The IFI, of course, does not want to waste its resources and, therefore, offers an assistance package that is just "barely attractive" for the government to accept. The paper shows that such barely attractive conditional assistance programs must always fail in their attempt to bring about economic reforms. The program is good enough for the government to accept assistance, but it is not good enough for the government to reform and forego future political support from the interest group. Second, the IFI's 'cost' of achieving economic reforms as a condition for economic assistance critically hinges on how dependent the government's political support is on the interest group prior to the implementation of economic reforms. The more successful the interest group is in its rentseeking and the more of the rent it contributes to support the government, the more costly it is to reform the economy and to dislodge the interest group. On the other hand, the cost of reform is lowered when governments are more dependent on political support from the general public. Third, we compare the effectiveness of conditional and unconditional assistance programs when the IFI's objective is the maximization of the entire world's welfare. It is shown that viable conditional programs are always more effective than unconditional programs. However, unconditional programs offer an appropriate choice when conditional programs are no longer viable. While the viability of conditional assistance critically hinges on how dependent the government's political support is on the interest group, the viability of unconditional assistance is independent of the influence of the interest group. Accordingly, the IFI should not rigidly stick to offering conditional assistance only. It should offer a mix of conditional and unconditional assistance programs in order to assist its heterogeneous clientele.

\section{The Political Economy of The Assistance-Receiving Country}

There are three decision makers in this political economy model of conditional assistance provision. A domestic government chooses the assistance-receiving country's economic policies; a domestic interest group attempts to influence policy choices for its own benefit; and an IFI offers assistance that is contingent on reforming the economy. Assistance is provided thro ugh a loan that the country cannot obtain in the private market. Economic reforms entail the removal of policy distortions that favor the interest group. In addition to the three decision makers, there is the assistance-receiving country's general public. Its welfare, together with the interest group's welfare, critically shape the government's policy choices.

The government's objective is to retain power which, in turn, depends on political support from the interest group and the general public. The interest group can appropriate economic rents through the adoption of economic policies that distort the economy and hurt the general public. The group tries to retain this privileged position by influencing the government through financial contributions, $C$. The latter are valuable to the government as it needs funding to shape the general public's perceptions of the government's performance. Interest group and general public have conflicting objectives. The general public benefits from economic reforms; the interest group is hurt by them. A completely reformed economy eliminates all rents to the interest group and, thereby, eliminates the group. The general 
public's welfare is measured by its own income, which consists of national income adjusted for both loan repayments to the IFI and economic rents siphoned off by the interest group.

Let us define the country's national income by $x$ and the loan repayment by $z$. The resulting net national income, $(x-z)$, is split between the general public and the interest group. If an interest group exists, its appropriated rent is assumed to be a constant share, $0 \leq \gamma<1$, of net national income. When the interest group disappears, all of net national income accrues to the general public. The government's political support function takes the usual form ${ }^{11}$ of:

$$
G=C+a(1-\gamma)(x-z)
$$

where $G$ is a measure of political support and $0<a<1$ is a parameter that translates the public's net income, $(1-\gamma)(x-z)$, into political support for the government. ${ }^{12}$ The value of $a$ is less than unity, meaning that a dollar of income received by the general public generates less political support than a dollar of financial contributions paid to the government.

An assistance agreement between the government and IFI spells out the amount of loan provided and the amount of repayments to be made. Repayments are not fixed but depend on the state of the economy at the time repayments are due. When the agreement is signed, neither the government nor the IFI knows how the economy will be performing, as the economy's production is stochastic. Production depends on the economy's resource base, the amount of assistance received, $T$, and the realization of the state of nature. Assuming constant resources, the country's production function can be written as:

$$
x=g(T) y
$$

where $y$ denotes national income in the absence of assistance, when $g(0)=1$, and where $g(T)>1$ expresses the magnifying influence of assistance on national income for $T>0$. It is assumed that there are diminishing returns to the amount of assistance received, such that $g^{\prime}(T)>0$ and $g^{\prime \prime}(T)<0$ for all $T>0$. For given resources, production is stochastic. National income in the absence of assistance, $y$, is either high, $\bar{y}$, or low, $\underline{y}$. The value of $\Delta y=(\bar{y}-\underline{y})$ $>0$ serves as a measure of the economy's performance volatility.

${ }^{11}$ This form of the political support function was popularized by Grossman and Helpman (1994). A more general specification of the political support function was first introduced by Hillman (1982).

12 The general public benefits from the assistance program in two ways: First, the IFI loan raises national income in the recipient country beyond what it would be under sole reliance on private capital markets. Second, the implementation of economic reforms raises expected national income and destroys (or at least weakens) the interest group, thereby enlarging the public's share of national income. The political-support-seeking government weighs this gain to the general public against the loss from vanishing interest group contributions. 
All economic agents are able to observe and verify the value of actual national income. While none of them knows with certainty the cause for income being high or low, it is common knowledge that economic reforms - with the effect of removing interest-groupbenefiting policy distortions - make the high-output state of nature more likely. More precisely, $0<\pi_{1}<1$ is defined as the probability of attaining high output when the economy is reformed, and $0<\pi_{0}<1$ is the probability of attaining high output when the economy is distorted. The value of $\left(\pi_{1}-\pi_{0}\right)=\Delta \pi>0$ serves as a measure of the effectiveness of economic reforms.

The IFI's assistance agreement spells out the assistance-receiving country's repayment obligations. In specifying repayment conditions, the IFI is concerned with the loan agreement's impact on the country's political stability. In particular, it fears that the general public will blame the conditional assistance agreement for having made the country worse off than it would have been without this agreement. Political stability is seriously threatened when the general public views the assistance agreement as an externally-imposed burden on the country. Securing political stability requires flexible loan repayment conditions.

Repayments when income is high, $\bar{z}$, and when income is low, $\underline{z}$, must be such that welfare of the general public is always at least as large under the assistance agreement as it would be without it. For future reference, we will attach subscript $\mathrm{i}=1$ to the loan variable $T_{\mathrm{i}}$ and repayments $z_{i}$ when the loan is conditional, while subscript $i=0$ is employed to indicate unconditional assistance.

In the early sections of this paper, we are not trying to determine what kind of conditional assistance program is 'optimal'. In fact, the IFI's ultimate objective in extending a loan to a country's government is not explicitly stated. Instead, these sections focus on the viability of the instrument through which the IFI wants to operate. The instrument is conditional assistance, meaning assistance that is contingent on the implementation of economic reforms. Use of the conditional assistance process implies a set of constraints that must be satisfied to ensure the loan-receiving country's implementation of economic reforms. The IFI's objective function is specified later, after the requirements for viable conditional assistance have been established, and the paper compares the effectiveness of conditional assistance with that of unconditional assistance. The IFI's objective is assumed to be the maximization of world welfare, consisting of combined welfare of assistance-receiving and assistance-providing countries.

\section{The INTEREST GROUP AS AN OBSTACLE TO ECONOMIC REFORMS}

Prior to the IFI-government loan agreement, the country under consideration is saddled with significant economic policy distortions. These distortions are the result of rent seeking by an interest group. The group makes financial contributions, $C$, to the policy-setting government in return for rent-generating policies. As stated earlier, a successful interest group's rent is assumed to be a constant fraction, $\gamma$, of national income net of loan repayments. As long as there are no reforms, $\pi=\pi_{0}$, and the interest group exerts influence. The group's expected net benefit from supporting a government that does not reform is: 


$$
\gamma\left\{\pi_{\mathrm{o}}\left[g\left(T_{\mathrm{o}}\right) \bar{y}-\bar{z}\right]+\left(1-\pi_{\mathrm{o}}\right)\left[g\left(T_{\mathrm{o}}\right) \underline{y}-\underline{z}\right]\right\}-C,
$$

where $T_{\mathrm{o}}>0$ and $z_{\mathrm{o}}>0$ when a loan is made and $T_{\mathrm{o}}=0=z_{\mathrm{o}}$ when there is no loan agreement.

Prior to the IFI's loan offer - when $T_{\mathrm{o}}=\bar{z}_{\mathrm{o}}=\underline{z}_{\mathrm{o}}=0$ in (3) - an interest group makes financial contributions to the government in return for rent-creating, distorting economic policies. The existence of such a group implies that expression (3) is nonnegative. If the group's expected net benefits were to become negative, its members would be better off if, instead of lobbying, they blended in as members of the general public. Accordingly, prior to receiving IFI assistance, there exists a maximum contribution level that the interest group is willing to make to avoid economic reforms. The maximum contribution equals the total rent generated by the distorting policies:

$$
\bar{C}^{\mathrm{o}}=\gamma\left\{\pi_{\mathrm{o}} \bar{y}+\left(1-\pi_{\mathrm{o}}\right) \underline{y}\right\},
$$

where the superscript "o" in $\bar{C}^{\circ}$ refers to this being the initial, pre-assistance outcome.

There also exists a minimum level of contribution, $\underline{C}^{0}$, which the interest group must make to prevent the government from reforming the economy on its own, even if it did not receive any assistance. For the government to retain distorting policies, political support from the interest group and the public's diminished well-being must be at least as strong as it would be if the government reformed the economy, eliminated the privileged position of the interest group, and thereby enhanced the public's well-being. Prior to the assistance agreement, expected political support for a nonreforming government is $\left\{C^{0}+a(1-\gamma)\left[\pi_{\mathrm{o}} \bar{y}+\left(1-\pi_{\mathrm{o}}\right) \underline{y}\right]\right\}$, as follows from equations (1) and (2). If, on the other hand, the government were to enact reforms and lost interest group support, its expected political support would become $a\left[\pi_{1} \bar{y}+\left(1-\pi_{1}\right) \underline{y}\right]$. Public support is enlarged not only by a rising expected national incomeas the probability of high national income increases - but also by getting all rather than only part of national income. On the other hand, the interest group's contribution has vanished. The minimum contribution the government must receive in order to work with the interest group, $\underline{C}^{0}$, is such that it makes the government indifferent between reforming and not reforming; that is,

$$
\underline{C}^{o}=a\left[\pi_{1} \bar{y}+\left(1-\pi_{1}\right) \underline{y}\right]-a(1-\gamma)\left[\pi_{\mathrm{o}} \bar{y}+\left(1-\pi_{\mathrm{o}}\right) \underline{y}\right]=a \Delta \pi \Delta y+a \gamma\left[\pi_{o} \bar{y}+\left(1-\pi_{\mathrm{o}}\right) \underline{y}\right] .
$$

The actual level of contributions, $C^{0}$, made by the interest group prior to the IFI's loan offer, depends on the bargaining power of the group in dealing with the government. We are not explicitly modeling this bargaining process. Instead, we assume that the actual contribution is a fixed fraction, $\beta$, of the maximum amount the interest group is willing to contribute, such that 


$$
\underline{C}^{\mathrm{o}}<C^{\mathrm{o}}=\beta \bar{C}^{\mathrm{o}} \leq \bar{C}^{\mathrm{o}}
$$

The condition that $\underline{C}^{\mathrm{o}}<C^{\mathrm{o}}=\beta \bar{C}^{\mathrm{o}}$ is implied by our assumption that, prior to the IFI's involvement, the interest group and the government benefited from supporting each other in the design of economic policies. It as follows from equations (4), (5), and (6) that

$$
A \equiv \gamma(\beta-a)\left\{\pi_{\mathrm{o}} \bar{y}+\left(1-\pi_{\mathrm{o}}\right) \underline{y}\right\}-a \Delta \pi \Delta y>0,
$$

where $A$ measures the interest group's actual political support of the government in excess of what is minimally required to prevent reforms. Note that this measure of the government's dependence on the interest group rises with both the share of income the group appropriates as rent, $\gamma$, and the bargaining strength of the government in dealing with the group, $\beta$; but this dependence declines with the public's influence on political support, as expressed by $a$. Later, the inequality (7) will be employed to determine which constraints of the conditional loan program are actually binding.

\section{Viability of Conditional Assistance Programs}

An IFI's conditional assistance offer consists of a loan that is contingent on the implementation of economic reforms. The loan must be repaid, and repayment conditions must be neither so harsh as to threaten the loan-receiving country's political stability nor so lenient as to compromise the IFI's financial stability. Most importantly, a conditional assistance program must contain incentives to implement reforms; it cannot simply be imposed by the IFI.

Viability requires the government not just to be willing to accept the loan and its repayment but also to implement the envisaged reforms. The IFI's offer must create the incentives to do so. It must be in the interest of the economic policy-setting government to reform the economy, even at the cost of losing support from a well-established and organized interest group. In creating the right incentives, the IFI faces an important additional concern. The incentive structure (repayment conditions) must not permit outcomes that endanger the country's political stability. More precisely, four constraints must be satisfied to create the necessary incentives to reform without endangering political stability. First, at the time the IFI makes a loan offer, the government must consider it advantageous to accept the IFIproposed conditional loan package. The government's expected political support with the loan and with economic reforms must be at least as strong as it would be without the loan and without economic reforms. This establishes a participation constraint. Second, the moral hazard problem of implementing economic reforms must be addressed. The government must have an incentive to implement real reforms. Real rather than apparent reforms are required. It is not sufficient to pass laws and regulations that project the appearance of a reformed economy. The laws and regulations must also be fully implemented and enforced to make them effective. While the IFI is able to observe the passage of economic reform laws and the economy's performance, it is unable to observe the actual implementation of reform measures. Only the domestic government and the domestic interest group know whether real 
reforms have been implemented. It is in the government's own interest to reform if expected political support is at least as strong when it accepts assistance and implements reforms as it would be with the same assistance and no implementation of reforms. In other words, there must be an incentive constraint to guarantee that it does not pay for the government to cheat on the assistance agreement.

The third and fourth constraints are needed to secure political stability. A country's public inevitably views external interference in the government's economic policymaking with concern. The adoption of external policy advice is rarely challenged if it seems to help the entire country. But the adoption of such advice becomes a major source of political instability if it seems to have hurt the country. Specifically, a threat to political stability emerges if, at any time during the assistance period, the public believes the country to have become worse off with the conditional loan than it would have been without such a loan. Different from the government's political support considerations, what matters here are not expectations about becoming better off or worse off through the acceptance of IFI assistance. What matters are actual outcomes. The IFI must structure the loan repayment conditions in a way that, no matter what the prevailing state of the economy, the public can never blame the IFI as having made the country worse off. Hence, there are two political stability constraints, one when actual income is high and one when actual income is low.

For any given conditional loan, viability definitely requires that the participation constraint, incentive constraint, and two political stability constraints are satisfied. If any one of these constraints is violated, the conditional loan program is doomed to fail. Repayment conditions that satisfy these four constraints face one additional hurdle. They also must be viable from the IFI's perspective. They must generate enough expected repayments to protect the IFI's own financial strength. In other words, the conditional assistance package must be such that the expected repayment is at least as large as the initial loan value. The relevant measure for assessing IFI financial stability is expected rather than actual repayments, since the IFI lends to many different countries and, depending on actual performance of these economies, earns a positive return on some loans and incurs a loss on other loans. As long as the IFI breaks even on average, it retains its financial strength.

We now provide detailed specifications of the constraint set that describes a viable conditional loan program. Starting with the participation constraint, the government is willing to accept a conditional assistance package if the loan and its repayment obligations, combined with the impact of economic reforms, are such that political support for the government is not weakened. The alternative to accepting conditional assistance is the status quo, in which the interest group makes financial contributions to the government and the economy remains distorted. The government's expected political support under this status quo is expressed by the right-hand side (RHS) of expression (8), whereby we set $g(0)=1$, the probability of high income is $\pi_{\mathrm{o}}$, and only $(1-\gamma)$ of national income is left for the general public. The left-hand side (LHS) of expression (8) states the expected political support for the government when it receives a conditional loan in the amount of $T_{1}>0$ and it is obligated to pay back $\bar{z}_{1}$ when the economy performs well and $\underline{z}_{1}$ when it performs poorly. The implementation of economic reforms raises the probability of the economy performing well 
from $\pi_{\mathrm{o}}$ to $\pi_{1}$, and the disappearance of the interest group raises the general public's share of national income from $(1-\gamma)$ to 1 . The government's participation constraint, therefore, is:

$$
A\left\{\pi_{1}\left[g\left(T_{1}\right) \bar{y}-\bar{z}_{1}\right]+\left(1-\pi_{1}\right)\left[g\left(T_{1}\right) \underline{y}-\underline{z}_{1}\right]\right\} \geq a(1-\gamma)\left[\pi_{\mathrm{o}} \bar{y}+\left(1-\pi_{\mathrm{o}}\right) \underline{y}\right]+C^{\mathrm{o}}
$$

The preceding section determined the interest group's maximum contribution, $\bar{C}^{\text {o }}$. We then assumed that bargaining between government and interest group results in an actual contribution of $C^{\mathrm{o}}=\beta \bar{C}^{\mathrm{o}}$. Use of equation (4) and substitution for $C^{\mathrm{o}}$ enables us to rewrite the participation constraint as

$$
A\left\{\pi_{1}\left[g\left(T_{1}\right) \bar{y}-\bar{z}_{1}\right]+\left(1-\pi_{1}\right)\left[g\left(T_{1}\right) \underline{y}-\underline{z}_{1}\right]\right\} \geq[a+\gamma(\beta-\alpha)]\left[\pi_{\mathrm{o}} \bar{y}+\left(1-\pi_{\mathrm{o}}\right) \underline{y}\right] .
$$

Second, we introduce the incentive constraint. The government must have an incentive not just to accept the loan package's economic reform conditions but also to implement and enforce them. If the government accepts the loan and its repayment obligations, implements reforms, and loses interest group support, then $\pi=\pi_{1}, \gamma=1$, and $C^{1}=0$ as expressed by the political-support expression on the LHS of expression (9). If, on the other hand, the government accepts assistance and its repayment obligations but fails to implement reforms and, thereby, retains interest group support, then $\pi=\pi_{0}, 0<\gamma<1$ and $C>0$ as stated in the political-support expression on the RHS of (9). The incentive constraint, which requires the government to be at least as well off accepting the loan and implementing reforms as it would be accepting the loan without implementing reforms, is then

$$
\begin{gathered}
a\left\{\pi_{1}\left[g\left(T_{1}\right) \bar{y}-\bar{z}_{1}\right]+\left(1-\pi_{1}\right)\left[g\left(T_{1}\right) \underline{y}-\underline{z}_{1}\right]\right\} \geq \\
a(1-\gamma)\left\{\pi_{\mathrm{o}}\left[g\left(T_{1}\right) \bar{y}-\bar{z}_{1}\right]+\left(1-\pi_{\mathrm{o}}\right)\left[g(T) \underline{y}-\underline{z}_{1}\right]\right\}+C^{1},
\end{gathered}
$$

where $C^{1}$ is the contribution level when assistance is received but there is no reform. The interest group's contribution, $C^{1}$, is again a fraction, $\beta$, of the maximum contribution the group is willing to make, $\bar{C}^{1}$. When the country did not receive any loans, this maximum contribution was described as $\bar{C}^{\text {o }}$ by equation (4). When the country now does receive a repayable loan, then the maximum contribution becomes

$$
\bar{C}^{1}=\gamma\left\{\pi_{o}\left[g\left(T_{1}\right) \bar{y}-\bar{z}_{1}\right]+\left(1-\pi_{\mathrm{o}}\right)\left[g\left(T_{1}\right) \underline{y}-\underline{z}_{1}\right]\right\}
$$

Substitution of $C^{1}=\beta \bar{C}^{1}$ and of equation (4') in (9) yields: 


$$
\begin{gathered}
a\left\{\pi_{1}\left[g\left(T_{1}\right) \bar{y}-\bar{z}_{1}\right]+\left(1-\pi_{1}\right)\left[g\left(T_{1}\right) \underline{y}-\underline{z}_{1}\right]\right\} \geq \\
{[a+\gamma(\beta-\alpha)]\left\{\pi_{\mathrm{o}}\left[g\left(T_{1}\right) \bar{y}-\bar{z}_{1}\right]+\left(1-\pi_{\mathrm{o}}\right)\left[g\left(T_{1}\right) \underline{y}-\underline{z}_{1}\right]\right\} .}
\end{gathered}
$$

The third and fourth of our viability constraints require the loan package not to threaten the country's political stability. As stated previously, the loan repayment conditions must be such that, independent of the state of the economy, the public can never blame the IFI for having made the country worse off. ${ }^{13}$ Hence, the country's actual income after loan repayment must be at least as large as its income would be if no loan had been received; and this must be so in good as well as in bad times. Accordingly, the political stability constraints are

$$
g\left(T_{1}\right) \bar{y}-\bar{z}_{1} \geq \bar{y}
$$

and

$$
g\left(T_{1}\right) \underline{y}-\underline{z}_{1} \geq \underline{y} .
$$

Given a conditional loan of value $T_{1}>0$, constraints $\left(8^{\prime}\right),\left(9^{\prime}\right),(10)$, and (11) can be used to solve for the highest attainable repayments, $\bar{z}_{1}$ and $\bar{z}_{1}$, that make the government accept the loan, induce it to implement reforms, and do not threaten the country's political stability. The IFI's choice is further narrowed by the condition that, given $T_{1}>0$, the solutions for $\bar{z}_{1}$ and $\underline{z}_{1}$ must be such that the IFI's budget constraint is satisfied; that is, the expected loan repayment must be at least as large as the actual amount of the conditional loan:

$$
\left[\pi_{1} \bar{z}_{1}+\left(1-\pi_{1}\right) \underline{z}_{1}\right] \geq T \text {. }
$$

\section{A Likely Scenario for Program Failure}

A typical IFI's general mission is to assist developing countries through loans that are not available in private capital markets. In pursuit of this mission, the IFI faces two major concerns. One is to help governments avoid procrastination by making loan offers that succeed in bringing as many of them to the negotiating table as possible. The other is to specify the loans' repayment conditions in a way to meet its own budget constraints. This leads to a natural inclination on the part of IFI negotiators to offer as many loan agreements as possible and to make them just attractive enough for governments to accept them. In other

${ }^{13}$ As discussed in the introduction to the paper, it is the ex post performance of the economy that matters for political stability of the country. In contrast, the government's decision to accept the assistance package is based on ex ante considerations. 
words, there is pressure or at least an inclination to offer conditional loan packages that make the participation constraint "just binding." That way, repayments are as large as possible to build the pool for offering the largest possible number of loans. Of course, both governments and IFI remain concerned with a country's political stability and, therefore, agree on repayment conditions that satisfy both political stability constraints.

With pressure to have many governments sign conditional agreements and to waste as little as possible, the incentive constraint becomes a likely candidate for neglect. In addition, satisfying the incentive constraint encounters the following obstacle. In the real world, it is far more difficult to quantify the conditions under which a conditional loan package meets the incentive constraint than it is to figure out whether the participation constraint is satisfied. When the government signs the loan agreement, the participation constraint is met. There is no such clear-cut signal for meeting the incentive constraint. An examination of the incentive constraint requires far more information. Not only must the IFI know how reforms enhance the prospect of a well-performing economy, it also must know how entrenched the country's interest group is. In light of these information problems concerning the incentive constraint, it is highly likely that the IFI puts primary emphasis on the participation constraint.

Given the IFI's inclination to make the participation constraint binding, this section establishes the following implication for conditional loan programs.

\section{Proposition 1}

A conditional loan offer inevitably results in reform failure if it is just barely attractive to the accepting government. When the participation constraint is binding and the political stability constraints are satisfied, the incentive constraint is always violated.

This proposition highlights the dangers of being preoccupied with signing loan agreements that preserve the IFI's financial and the recipient country's political stability. The temptation is to offer a deal that is just good enough to bring a government to the table. The government willingly accepts the loan and agrees to the repayments, but has no incentive to implement and enforce reforms. Its incentive is to cheat on the implementation of economic reforms. As shown in the next section, more lenient repayment conditions are called for to induce reforms. In other words, the IFI must allow for additional cost when it wants to induce economic reforms. This additional cost weighs, of course, on the IFI's budget constraint. It is quite possible that there exists no loan package that meets the IFI's budget constraint when the loan is conditional, even though the constraint could be met if the loan were unconditional. The latter comparison will be taken up in Section VII.

To prove Proposition 1, we have the IFI offer a deal that is just good enough to be acceptable to the government; that is, the participation constraint of $\left(8^{\prime}\right)$ is binding. Furthermore, concern for political stability requires that constraints (10) and (11) are satisfied. To show that these three constraints necessarily imply that incentive constraint $\left(9^{\prime}\right)$ is violated, we write $\left(8^{\prime}\right)$ as an equality and substitute the RHS of $\left(8^{\prime}\right)$ in the LHS of $\left(9^{\prime}\right)$ to obtain:

$$
\left[\pi_{\mathrm{o}} \bar{y}+\left(1-\pi_{\mathrm{o}}\right) \underline{y}\right] \geq\left\{\pi_{\mathrm{o}}\left[g\left(T_{1}\right) \bar{y}-\bar{z}_{1}\right]+\left(1-\pi_{o}\right)\left[g\left(T_{1}\right) \underline{y}-\underline{z}_{1}\right]\right\}
$$


After subtracting $\left[\pi_{\mathrm{o}} \bar{y}+\left(1-\pi_{\mathrm{o}}\right) \underline{y}\right]$ from both sides, the incentive constraint becomes

$$
0 \geq\left\{\pi_{\mathrm{o}}\left[\bar{y} \Delta g_{1}-\bar{z}_{1}\right]+\left(1-\pi_{o}\right)\left[\underline{y} \Delta g_{1}-\underline{z}_{1}\right]\right\},
$$

where $\Delta g_{1}=\left[g\left(T_{1}\right)-1\right]>0$. From the political stability constraints (10) and (11) one can see that both terms on the RHS of $\left(9^{\prime \prime}\right)$ are nonnegative and that the incentive constraint of $\left(9^{\prime \prime}\right)$ would be satisfied only if both (10) and (11) were binding. But this cannot be. The participation constraint of $\left(8^{\prime}\right)$, when written as an equality, implies that both political stability constraints cannot be binding. This can be seen after subtracting $a\left[\pi_{1} \bar{y}+\left(1-\pi_{1}\right) \underline{y}\right]$ from both the LHS and RHS of ( $\left.8^{\prime}\right)$, and using (7):

$$
a\left\{\pi_{1}\left[\bar{y} \Delta g_{1}-\bar{z}_{1}\right]+\left(1-\pi_{1}\right)\left[\underline{y} \Delta g_{1-} \underline{z}_{1}\right]\right\}=A>0,
$$

where we use (7) to sign the expression. Hence, the fact that, prior to accepting assistance, an interest group influenced the government's policies implies that both $\left[\bar{y} \Delta g_{1}-\bar{z}_{1}\right]$ and $\left[\underline{y} \Delta g_{1}-\underline{z}_{1}\right]$ are nonnegative and at least one of them is positive. This, in turn, implies that the incentive constraint of $\left(9^{\prime \prime}\right)$ must be violated. The government has an incentive to cheat on the implementation of reforms.

\section{THE GOVERNMENT’s DEPENDENCE ON INTEREST GROUPS AND CONDITIONAL LOAN VIABILITY}

A conditional loan program is viable if the government has incentives to accept the loan and to implement economic reforms without threatening the country's political stability and the IFI's solvency. The main goal of this section is to relate conditional loan viability to the government's dependency on the interest group. The government's dependency on the interest group rises with $0 \leq \gamma<1$, which denotes the fraction of the country's net income the group appropriates as economic rent, and with $\beta$, the government's share in this rent (the financial contributions it receives from the interest group).

To highlight the various influences on conditional loan viability, we first solve for the loan repayment conditions, $\bar{z}_{1}$ and $\underline{z}_{1}$, that satisfy the participation constraint $\left(8^{\prime}\right)$, the incentive constraint (9'), and the political stability constraints (10) and (11). As shown in the Appendix, the incentive constraint and the political stability constraint in the bad state of nature are binding, while the other two constraints are satisfied but not binding. Hence, we immediately know from (10) that:

$$
\underline{z}_{1}=\underline{y} \Delta g_{1}
$$


where $\underline{y} \Delta g_{1}=\underline{y}\left[g\left(T_{1}\right)-1\right]>0$ measures the loan-generated increase in national income in the bad state of nature. When income is low, the contractual repayment is exactly equal to the country's gain in income due to the loan.

The amount of repayment in the good state of nature is obtained by going to the binding incentive constraint as restated in equation (A.2) of the Appendix, substituting (13) and (7), and solving for

$$
\bar{z}_{1}=\bar{y} \Delta g_{1}-A / B
$$

where $B=\pi_{1} a-\pi_{\mathrm{o}}[\beta \gamma+a(1-\gamma)]$. The first term on the RHS of expression (14) measures the gain in good-state-of-nature income made possible by the loan. $A>0$ is, as explained earlier, a measure of the government's dependence on political support from the interest group. And the term $B$ is positive since $\pi_{1} a$ must exceed $\pi_{\mathrm{o}}[\beta \gamma+a(1-\gamma)]$ when reforms are actually implemented. $^{14}$

The government's political dependence on the interest group, as measured by the value of $A$, represents an important influence on the magnitude of the good-state of nature repayment. The more dependent the government is on interest group support, the smaller is its repayment requirement in the good state of nature. As mentioned already, this political dependency is directly related to the interest group's ability to capture rent, $\gamma$, and the government's ability to share in this rent, $\beta$. It is negatively related to the importance of support from the public, as expressed by the value of $a$. More generally, one can state the following.

${ }^{14}$ The political stability constraint in the unfavorable state of nature is always binding, and the assistance-receiving country can raise its net income from assistance only when the favorable state of nature comes about. This favorable state comes about with probability $\pi_{1}$ when the economy is reformed and with probability $\pi_{\mathrm{o}}$ when there are no reforms. With reforms, the interest group collapses and all extra income goes to the public which, in turn, generates $a$ of political support from each extra unit of income gained. Hence, the expected gain in political support to the government from another unit of income gained by the reformed economy is $\pi_{1} a$. With no reforms, the interest group retains influence, gains $\gamma$ of each additional unit of income, and contributes $\beta \gamma$ per unit of national income to the government. In addition, the government receives political support from the public equal to $a(1-\gamma)$ per unit of income gain. Hence, the expected gain in political support from another unit of income gained by the unreformed economy is $\pi_{\mathrm{o}}[\beta \gamma+a(1-\gamma)]$. For the government to accept assistance and implement reforms, it must be that $\pi_{1} a>\pi_{\mathrm{o}}[\beta \gamma+a(1-\gamma)]$. 


\section{Proposition 2}

The more successful the interest group is in appropriating rent, the more successful the government is in sharing this rent in the form of financial contributions, and the less important the general public is in the political calculus of the government, the smaller is the assistance-receiving government's repayment to the IFI and the more likely it is that the IFI's financial stability constraint is violated.

The IFI's budget constraint was stated in (12). After substitution of (13) and (14), financial stability of the IFI requires that:

$$
E\left[z_{1}\right] \equiv \pi_{1} \bar{z}_{1}+\left(1-\pi_{1}\right) \underline{z}_{1}=\left[\pi_{1} \bar{y}+\left(1-\pi_{1}\right) \underline{y}\right] \Delta g_{1}-\pi_{1} A / B \geq T_{1}
$$

To satisfy the budget constraint, the expected loan repayment must be at least as large as the value of the loan. Expected repayment, in turn, equals the expected gain in income from the loan when the economy is reformed minus a term whose value rises with the government's dependence on the interest group. More specifically, one can show that $\partial E\left(z_{1}\right) / \partial \gamma<0$ and $\partial E\left(z_{1}\right) / \partial \beta<0$, whereas $\partial E\left(z_{1}\right) / \partial a>0$. Finally, we note that it is quite likely that the extra cost of creating incentives to reform the economy is sufficiently high for the IFI's budget constraint to be violated when the expected return on a conditional loan is rather small. This is particularly likely when there are strong bonds between interest group and government.

\section{Is UnConditional Assistance AN Alternative?}

Offering a loan that is contingent on reforming the economy is not the only way of assisting a country. There exists the alternative of offering unconditional assistance, when the IFI provides a loan without making it contingent on the implementation of economic reforms. This section examines the effectiveness of unconditional assistance relative to viable conditional assistance, as well as the use of unconditional loans when conditional loans are no longer viable.

Comparing the effectiveness of alternative assistance instruments requires specification of an objective function for the IFI. We assume here that the IFI's goal is to maximize expected income of the entire world, which consists of the loan-receiving country under consideration and the loan-providing rest of the world. Expected net income of the loan-receiving country is expected income after having received assistance minus expected repayments:

$$
g\left(T_{\mathrm{i}}\right)\left[\pi_{\mathrm{i}} \bar{y}+\left(1-\pi_{\mathrm{i}}\right) \underline{y}\right]-\left[\pi_{i} \bar{z}_{\mathrm{i}}+\left(1-\pi_{\mathrm{i}}\right) \underline{z}_{\mathrm{i}}\right\}
$$

where $\mathrm{i}=0$ when assistance is unconditional and the economy is not reformed and $\mathrm{i}=1$ when assistance is conditional and the economy is reformed. Expected net income of the rest of the world is: 


$$
E\left[Y^{*}\right]-T_{\mathrm{i}}+\left[\pi_{\mathrm{i}} \bar{z}_{\mathrm{i}}+\left(1-\pi_{\mathrm{i}}\right) \underline{z}_{\mathrm{i}}\right]
$$

where $E\left[Y^{*}\right]$ denotes the rest of the world's expected income in the absence of any assistance provision. The objective function of the IFI, therefore, is:

$$
W\left(T_{\mathrm{i}}\right)=g\left(T_{\mathrm{i}}\right)\left[\pi_{\mathrm{i}} \bar{y}+\left(1-\pi_{\mathrm{i}}\right) \underline{y}\right]+E\left[Y^{*}\right]-T_{\mathrm{i}},
$$

where $W\left(T_{\mathrm{i}}\right)$ denotes expected income of the world as a whole when assistance is $T_{\mathrm{i}}$. The IFI's goal is to maximize $W\left(Y_{\mathrm{i}}\right)$ with respect to $T_{\mathrm{i}}$, without compromising the assistancereceiving country's political and the IFI's financial stability. With conditional assistance, there is the additional requirement that the repayment conditions contain sufficient incentives for the government to implement the called-for economic reforms.

For conditional assistance, the relevant constraint set was specified and discussed in Section IV. Viability of conditional assistance required that the IFI's reduced-form financial stability constraint, as stated in (15), is satisfied. We now restate this condition as:

$$
E\left[Y_{1}\right] g\left(T_{1}\right)-\left[E\left(Y_{1}\right)+R+T_{1}\right] \geq 0
$$

where $E\left[Y_{1}\right]=\left[\pi_{1} \bar{y}+\left(1-\pi_{1}\right) \underline{y}\right]$ denotes expected income of the reformed economy in the absence of assistance, $\left[g\left(T_{1}\right)-1\right]=\Delta g_{1}$, and $R=\pi_{1} A / B>0$ is the expected limited liability rent. The IFI maximizes its objective function of (18), setting $i=1$, subject to the constraint of $\left(15^{\prime}\right)$. The Kuhn-Tucker conditions require that:

$$
E\left[Y_{1}\right] g^{\prime}\left(T_{1}^{*}\right) \leq 1
$$

and that (15) holds at $T_{1}{ }^{*}$, where $T_{1}{ }^{*} \geq 0$ denotes the IFI's world welfare-maximizing choice of conditional assistance. If $E\left[Y_{1}\right] g^{\prime}(0)>1$, such that making a small transfer from the rest of the world to a reformed developing economy raises world welfare, then $T_{1}{ }^{*}>0$ as long as the IFI's financial stability constraint of (15') is satisfied. If, on the other hand, the expected limited liability rent $R$ is so high that the IFI's financial stability is compromised, then no conditional assistance will be forthcoming. ${ }^{15}$ The more rent the interest group appropriates in the absence of reforms, the more the government shares in this rent, and the less influential the general public is, the larger is $R$ and the more likely it is that the IFI cannot afford to offer conditional assistance.

${ }^{15}$ Note that (15') is always satisfied when $E\left[Y_{1}\right] g^{\prime}(0)>1$ and $R=0$ since $g^{\prime \prime}(T)<0$. 
For unconditional assistance, equation (18) serves again as the objective function of the IFI, setting $\mathrm{i}=0$. The constraint set under unconditional assistance, however, is quite different from the constraint set under conditional assistance, since the IFI no longer is concerned with creating incentives for the government to reform. Consequently, the interest group remains active even after assistance is given. There no longer is an incentive constraint, and the participation constraint becomes:

$$
a(1-\gamma)\left\{\pi_{\mathrm{o}}\left[g\left(T_{\mathrm{o}}\right) \bar{y}-\bar{z}_{\mathrm{o}}\right]+\left(1-\pi_{\mathrm{o}}\right)\left[g\left(T_{\mathrm{o}}\right) \underline{y}-\underline{z}_{\mathrm{o}}\right]\right\}+\beta \bar{C}^{2} \geq a(1-\gamma)\left[\pi_{\mathrm{o}} \bar{y}+\left(1-\pi_{\mathrm{o}}\right) \underline{y}\right]+\beta \bar{C}^{\mathrm{o}},
$$

where $\bar{C}^{2}=\gamma\left\{\pi_{\mathrm{o}}\left[g\left(T_{\mathrm{o}}\right) \bar{y}-\bar{z}_{\mathrm{o}}\right]+\left(1-\pi_{\mathrm{o}}\right)\left[g\left(T_{\mathrm{o}}\right) \underline{y}-\underline{z}_{\mathrm{o}}\right)\right\}$ and $\bar{C}^{\mathrm{o}}=\gamma\left\{\pi_{\mathrm{o}} \bar{y}+\left(1-\pi_{\mathrm{o}}\right) \underline{y}\right\}$ are the maximum interest group contributions in the absence of reforms with and without an unconditional loan, respectively. Substitution of these contribution expressions reduces (20) to:

$$
\left\{\pi_{\mathrm{o}}\left[\bar{y} \Delta \mathrm{g}_{\mathrm{o}}-\bar{z}_{\mathrm{o}}\right]+\left(1-\pi_{\mathrm{o}}\right)\left[\underline{y} \Delta g_{\mathrm{o}}-\underline{z}_{\mathrm{o}}\right]\right\} \geq 0
$$

where $\Delta \mathrm{g}_{\mathrm{o}}=\left[g\left(T_{\mathrm{o}}\right)-1\right]$. In addition to $\left(20^{\prime}\right)$, the political stability constraints of (10) and (11), as well as the IFI's financial stability constraint of (12) must be satisfied, with the only modification that loan repayments in the favorable and unfavorable state of nature are now $\bar{z}_{\mathrm{o}}$ and $\underline{z}_{\mathrm{o}}$, respectively, rather than $\bar{z}_{1}$ and $\underline{z}_{1}$.

Appendix II shows that, for the amount of unconditional assistance that maximizes the objective function of (18), $T_{\mathrm{o}}{ }^{*}$, there exists a non-empty set of loan repayment values, $\bar{z}_{\mathrm{o}}$ and $\underline{z}_{0}$, such that the participation, political stability, and IFI financial stability constraints are met. Accordingly, the IFI's world welfare-maximizing amount of unconditional assistance is determined by the following condition.

$$
E\left[Y_{\mathrm{o}}\right] g^{\prime}\left(T_{\mathrm{o}}^{*}\right) \leq 1
$$

where $T_{\mathrm{o}}^{*}>0$ if $E\left[Y_{\mathrm{o}}\right] g^{\prime}(0)>1$.

We are now in a position to evaluate what form of assistance maximizes the world's welfare, as stated in the following.

\section{Proposition 3}

a. Selectivity in the provision of assistance: If the expected net return on conditional assistance is non-positive at all assistance levels, then neither conditional nor unconditional assistance is provided; that is, if $E\left[Y_{1}\right] g^{\prime}(0) \leq 1$, then $T_{1}{ }^{*}=T_{o}{ }^{*}=0$. 
b. Conditional assistance is best: If the expected net return on conditional assistance is positive for some assistance level and the limited liability rent is sufficiently small, then $T_{1}{ }^{*}>T_{o}{ }^{*}$ and conditional assistance yields higher world welfare than unconditional assistance; that is, if $E\left[Y_{1}\right] g^{\prime}(0)>1$ and $R$ is sufficiently small, then $T_{1}{ }^{*}>T_{o}{ }^{*}$ and $W\left(T_{1}{ }^{*}\right)>W\left(T_{o}^{*}\right)$.

c. Unconditional assistance is best: If the expected net return on unconditional assistance is positive for some assistance level and the limited liability rent under conditional assistance is sufficiently large, then it is best for the IFI to give assistance without attaching conditions; that is if $E\left[Y_{o}\right] g^{\prime}(0)>1$ and $R$ is sufficiently large, then $T_{1}{ }^{*}=0<T_{o}{ }^{*}$.

Part (a) of Proposition 3 follows directly from (19) and (21) and the fact that $E\left[Y_{1}\right]>E\left[Y_{\mathrm{o}}\right]$. Parts (b) and (c) can be explained with the help of Figure 1 which traces the $E\left[Y_{\mathrm{i}}\right] g(T)$ functions for $i=0,1$. The choice of conditional assistance is determined by equation (19) which requires that the slope of the $E\left[Y_{1}\right] g(T)$ function is equal to unity. The tangency point is marked by $A_{1}$, yielding conditional assistance $T_{1}{ }^{*}>0$, provided the IFI's financial stability constraint (15') is satisfied. Distance $\mathrm{A}_{1} \mathrm{C}$ measures $E\left[Y_{1}\right] g\left(T_{1}{ }^{*}\right)$, while distance $\mathrm{BC}$ measures the value of $E\left[Y_{1}\right]+T_{1}{ }^{*}$. If the limited liability rent is sufficiently small, such that $R$ is less than distance $\mathrm{A}_{1} \mathrm{~B}$, then $T_{1}{ }^{*}>0$ is the optimal choice. If, on the other hand, the limited liability rent is so large that $R$ exceeds distance $\mathrm{A}_{1} \mathrm{~B}$, then no conditional assistance is provided. The choice of unconditional assistance is determined by equation (21) which requires that the slope of the $E\left[Y_{\mathrm{o}}\right] g(T)$ function is equal to unity. This happens at point $\mathrm{A}_{\mathrm{o}}$, yielding unconditional assistance $T_{\mathrm{o}}{ }^{*}>0$. Since $E\left[Y_{\mathrm{o}}\right] g^{\prime}(T)<E\left(Y_{1}\right) g^{\prime}(T)$ for all $T$, it must be that $T_{1}^{*}>T_{\mathrm{o}}^{*}>0$ as long as $E\left[Y_{\mathrm{o}}\right] g^{\prime}(0)>1$.

When the IFI's choice for both conditional and unconditional assistance is positive, world welfare under conditional assistance, $W\left(T_{1}{ }^{*}\right)$, must always exceed world welfare under unconditional assistance, $W\left(T_{\mathrm{o}}{ }^{*}\right)$; that is,

$$
E\left[Y_{1}\right] g\left(T_{1}^{*}\right)+E\left[Y^{*}\right]-T_{1}^{*}>E\left[Y_{\mathrm{o}}\right] g\left(T_{\mathrm{o}}^{*}\right)+E\left[Y^{*}\right]-T_{\mathrm{o}}^{*}
$$

To show this, we add and subtract $E\left[Y_{1}\right] g\left(T_{\mathrm{o}}{ }^{*}\right)$ on the LHS of equation (22) and rewrite it as:

$$
\left[E\left[Y_{1}\right] g\left(T_{1}^{*}\right)-T_{1}^{*}\right]-\left[\mathrm{E}\left[Y_{1}\right] g\left(T_{\mathrm{o}}^{*}\right)-T_{\mathrm{o}}^{*}\right]+\left[E\left[Y_{1}\right] g\left(T_{\mathrm{o}}^{*}\right)-E\left[Y_{\mathrm{o}}\right] g\left(T_{\mathrm{o}}^{*}\right)\right]>0
$$

Equation (22') must hold since, evaluated at $E\left[Y_{1}\right]$, the first bracketed term on the LHS of $\left(22^{\prime}\right)$ must always exceed the second bracketed term. That is so, because the value of $\left[E\left[Y_{1}\right] g(T)-T\right]$ is maximized when $T_{1}{ }^{*}$ rather than $T_{\mathrm{o}}{ }^{*}$ is chosen. Furthermore, the third bracketed term must be positive since $E\left[Y_{1}\right]>E\left[Y_{\mathrm{o}}\right]$. 


\section{CONCLUDING REMARKS}

IFI-supported programs have a mixed record of accomplishing their objectives. While IFIs almost always succeed in getting repaid, the policy programs supported by IFI loans do not always succeed in their objective of reforming recipient countries' economies. This paper has argued that asymmetries of information and the influence of special interests are at the root of such failures. Our model illustrated the relationship between an assistance-receiving country whose economic policies are distorted by the influence of a special interest group and an assistance-providing IFI that is willing to assist conditional on the implementation of economic reforms. In the absence of conditional assistance, the government has no incentive to adopt economic reforms. A domestic interest group backs the government and earns economic rents from distorted economic policies. For IFI-supported programs to succeed in delivering economic reforms, the interest group must lose this privileged position.

The model illustrates the difficult trade-offs that must be considered in designing IFIsupported programs. To be viable, programs must strike a balance in meeting several objectives relating to the borrowing country, its government, and the IFI. The government must have an incentive to come to the IFI for support (the participation constraint) and also to implement the agreed reforms (the incentive constraint). The program must also ensure that the entire country's political stability is maintained (the political stability constraints), and it must safeguard the IFI's resources (the IFI financial constraint).

As Proposition 1 demonstrates, conditional assistance programs that are just attractive enough for a government to accept, without endangering the country's political and the IFI's financial stability, always fail in the sense of resulting in no reforms. This type of nonviable conditional program serves no one's interests. The country is not able to reform, and the program's consequences for national welfare, growth, and distribution are adverse. Also, important, programs that are intended to reform but fail to do so hurt the IFI's own credibility. This, in turn, hurts the quality of the IFI's seal of approval function and the effectiveness of its catalytic effect on private capital flows. Programs that do not result in effective reform may also necessitate successor programs, resulting in inappropriate prolonged use of IFI financing. ${ }^{16}$

The extent of the IFI's information gap is one of the "fundamentals" that affects its decision to provide conditional assistance. If the information rent accruing to the interest groupinfluenced government becomes too high, then it is not worthwhile to provide assistance. This suggests that IFIs, when they deal with very opaque governments and undecipherable economic environments, must allow for selectivity, as has been observed in practice. Improvements in information technology and international policy initiatives during the past decade have greatly increased the transparency of economic data and policies worldwide. This development is bound to reduce the IFI's informational disadvantage and the

${ }^{16}$ Some prolonged users of IFI resources fit this category. Governments have signed a number of reform programs with IFIs, and IFIs have disbursed loans, only for countries to backtrack, slow down, or even reverse reforms. See IMF (2002b) or Svensson (2003). 
governments' information rents. This could lead to more viable conditional assistance programs being signed, a higher rate of implementation rate of IFI-supported reforms, and a curtailment of the power of vested interests.

Meeting a program's incentive constraint requires the recipient government to discontinue (or, in practice, to reduce the extent of) its privileged relationship with politically influential interest groups. A number of recent cases indicate that failure to ensure incentive compatibility is a practical problem. In recent years, a number of IFI borrowers have misreported information to IFIs and have inappropriately used the proceeds of IFI loans. IFIs, in turn, have responded by strengthening their procedures to deal with mis- and nonreporting of information and by strengthening the audits of central banks of borrowing countries (IMF, 2004a; IMF, 2000). While these technical steps are in the right direction and are helping to reduce the extent of the IFIs' information gap, they illustrate our analytical point that some programs fail to meet the incentive compatibility constraint.

Lack of incentive compatibility also results in reforms being reversed following the end of IFI loan disbursements. Naturally, not all reforms are reversible. IFIs can make a difference by insisting on the implementation of observable, hard-to-reverse reforms as a prior action to approving programs. But it is also true that many reforms can be attenuated or neutralized through backtracking and reversals. Better understanding of this issue calls for generalization of our model to a multiperiod framework.

Programs may be nonviable for reasons other than failure to meet incentive constraints. Breakdown of political stability is one possibility. IMF negotiators and their country counterparts are well positioned to assess the immediate dangers to political stability stemming from programmed reforms. Governments will not sign onto - and IFIs will not offer - programs that destabilize the country during their tenure in office. What happens after the end of loan disbursements is another matter. The paper highlights the need for programs to assess the prospects for political stability over a longer time horizon. The IFI loan repayment phase may be a long time after current IFI and country officials have left office. In practice, political stability is maintained at repayment time because IFIs are usually willing to negotiate loan programs with future governments. Successor programs give debtors additional breathing space by restructuring old debts and providing fresh IFI financing. Introducing short-sighted governments or IFI bureaucratic incentives into a repeated-game version of our framework is likely to give additional insights into the nature of the relationship between IFIs and their borrowers.

The paper also highlights the need for programs to safeguard the financial strength of the IFIs. There have been relatively few cases in which programs have failed to ensure the IFI's own financial integrity, presumably because IFIs are senior creditors and are also well aware of these constraints. IFIs have been exposed to significant financial risk in a few instances in which countries in social, political, and economic turmoil ran protracted arrears on their multilateral loans. Generally speaking though, failure to implement reforms does not result in stopping debt servicing to IFIs. Member countries continue making payments to IFIs even if they are under considerable financial and economic stress. But the incipient financial risk to IFIs is greater than suggested by the low frequency of such protracted arrears. In a number of 
cases, IFIs avoided incurring arrears only by resorting to defensive lending - rolling over maturing loans without requiring additional reforms as a quid pro quo.

The difficulties in meeting all constraints imposed by the requirement of program viability raises the question of whether there are ways to help a country avoid the pitfalls of conditional assistance. It is possible (Proposition 3) for the IFI to substitute unconditional loans for conditional loans when the strength of the interest group rises and conditional assistance fails to meet the IFI's budget constraint. Whether the IFI would want to lend to such a country is not addressed in this paper, since we did not specify an objective function for the IFI. It could be a scenario for lending to systemically important countries (those whose policy externalities affect significantly other countries). Because IFIs are rules-based institutions, uniformity of treatment considerations prevent them from formally abandoning conditionality in loans to such borrowers. But conditionality could be watered down in fact, if not in principle. 


\section{Constraint Set With Conditional Assistance}

This Appendix derives the binding viability constraints when assistance is conditional. It shows that the binding incentive constraint $\left(9^{\prime}\right)$ and the binding political stability constraint in the unfavorable state of nature (constraint (11)) imply that the participation constraint $\left(8^{\prime}\right)$ and the political stability constraint in the favorable state of nature (constraint (10)) are satisfied but not binding.

Stating $\left(9^{\prime}\right)$ as an equality and subtracting $a\left\{\pi_{\mathrm{o}}\left[g\left(T_{1}\right) \bar{y}-\bar{z}_{1}\right]+\left(1-\pi_{\mathrm{o}}\right)\left[g\left(T_{1}\right) \underline{y}-\underline{z}\right]\right\}$ from both sides, yields:

$$
a \Delta \pi\left\{\left[g\left(T_{1}\right) \bar{y}-\bar{z}_{1}\right]-\left[g\left(T_{1}\right) \underline{y}-\underline{z}_{1}\right]\right\}=\gamma(\beta-\alpha)\left\{\pi_{\mathrm{o}}\left[g\left(T_{1}\right) \bar{y}-\bar{z}_{1}\right]+\left(1-\pi_{\mathrm{o}}\right)\left[g\left(T_{1}\right) \underline{y}-\underline{z}_{1}\right]\right\}
$$

where $\Delta \pi=\left(\pi_{1}-\pi_{0}\right)>0$. Next, subtracting $a \Delta \pi(\bar{y}-\underline{y})$ from both sides of (A.1), and adding and subtracting $\gamma(\beta-\alpha)\left[\pi_{\mathrm{o}} \bar{y}+\left(1-\pi_{\mathrm{o}}\right) \underline{y}\right]$ on its RHS, results in:

$$
a \Delta \pi\left\{\left(\bar{y} \Delta g_{1}-\bar{z}_{1}\right)-\left(\underline{y} \Delta g_{1}-\underline{z}_{1}\right)\right\}=A+\gamma(\beta-\alpha)\left[\pi_{0}\left(\bar{y} \Delta g_{1}-\bar{z}_{1}\right)-\left(1-\pi_{0}\right)\left(\underline{y} \Delta g_{1}-\underline{z}_{1}\right)\right]
$$

where $A \equiv \gamma(\beta-a)\left\{\pi_{\mathrm{o}} \bar{y}+\left(1-\pi_{\mathrm{o}}\right) \underline{y}\right\}-a \Delta \pi \Delta y>0, \Delta y=(\bar{y}-\underline{y})>0$ and $\Delta g_{1}=\left[g\left(T_{1}\right)-1\right]>1$. The RHS of the above equation must be positive since expression (7) in the text guarantees that $A>0$, whereas $\left(\underline{y} \Delta g_{1}-\underline{z}_{1}\right)=0$ since (11) is binding and $\left(\bar{y} \Delta g_{1}-\bar{z}_{1}\right) \geq 0$ from (10). It follows that the LHS of (A.2) must be positive and that the political stability constraint in the favorable state of nature is not binding; that is:

$$
\left(\bar{y} \Delta g_{1}-\bar{z}_{1}\right)>0 \text {. }
$$

Checking the participation constraint of $\left(8^{\prime}\right)$, we substitute the RHS of the binding incentive constraint of $\left(9^{\prime}\right)$ in the LHS of $\left(8^{\prime}\right)$ and subtract $[a+\gamma(\beta-\alpha)]\left[\pi_{0} \bar{y}+\left(1-\pi_{0}\right) \underline{y}\right]$ from both sides of the restated participation constraint to obtain:

$$
\{a+\gamma(\beta-a)\}\left\{\pi_{o}\left[\bar{y} \Delta g_{1}-\bar{z}_{1}\right]+\left(1-\pi_{0}\right)\left[\underline{y} \Delta g_{1}-\underline{z}_{1}\right]\right\} \geq 0
$$

Since $\left[\bar{y} \Delta g_{1}-\bar{z}_{1}\right]>0$ and $\left[\underline{y} \Delta g_{1}-\underline{z}_{1}\right]=0$, the participation constraint is satisfied but not binding. 


\section{Constraint Set With Unconditional Assistance}

When assistance is unconditional, the constraint set consists of the government's participation constraint (A.5) - which simply restates equation $\left(20^{\prime}\right)$ of the text - the two political stability constraints (A.6) and (A.7), and the IFI's financial stability constraint (A.8):

$$
\begin{gathered}
\left\{\pi_{\mathrm{o}}\left[\bar{y} \Delta \mathrm{g}_{\mathrm{o}}-\bar{z}_{\mathrm{o}}\right]+\left(1-\pi_{\mathrm{o}}\right)\left[\underline{y} \Delta g_{\mathrm{o}}-\underline{z}_{\mathrm{o}}\right]\right\} \geq 0 \\
g\left(T_{\mathrm{o}}\right) \bar{y}-\bar{z}_{\mathrm{o}} \geq \bar{y} \\
g\left(T_{\mathrm{o}}\right) \underline{y}-\underline{z}_{\mathrm{o}} \geq \underline{y} \\
{\left[\pi_{\mathrm{o}} \bar{z}_{\mathrm{o}}+\left(1-\pi_{\mathrm{o}}\right) \underline{z}_{\mathrm{o}}\right] \geq T_{\mathrm{o}} .}
\end{gathered}
$$

First, one can see that (A.6) and (A.7) imply (A.5) since $\left[g\left(T_{0}\right)-1\right]=\Delta g_{0}$. Second, one can show that (A.6) and (A.7), when binding at the optimal unconditional assistance choice of $T_{\mathrm{o}}$, imply that (A.8) is always satisfied but not binding. This can be seen after writing (A.6) and (A.7) as equalities, substituting for $\bar{z}_{\mathrm{o}}$ and $\underline{z}_{\mathrm{o}}$ in (A.8), and restating (A.8) as follows.

$$
\left[E\left[Y_{\mathrm{o}}\right] g\left(T_{\mathrm{o}}^{*}\right)-E\left[Y_{\mathrm{o}}\right]\right] / T_{\mathrm{o}}^{*} \geq 1 \text {. }
$$

The optimal choice of $T_{\mathrm{o}}>0$, in turn, requires that $E\left[Y_{\mathrm{o}}\right] g^{\prime}\left(T_{\mathrm{o}}{ }^{*}\right)=1$; and strict concavity of the $g(T)$ function implies that $\left[E\left[Y_{\mathrm{o}}\right] g\left(T_{\mathrm{o}}^{*}\right)-E\left[Y_{\mathrm{o}}\right]\right] / T_{\mathrm{o}}{ }^{*}>E\left[Y_{\mathrm{o}}\right] g^{\prime}\left(T_{\mathrm{o}}{ }^{*}\right)=1$, as can be seen from Figure 1. Consequently, it must be that, for the value of $T_{\mathrm{o}}^{*},(\mathrm{~A} .8)$ is not binding for that combination of $\left(\bar{z}_{0}, \underline{z}_{0}\right)$ for which constraints (A.6) and (A.7) are binding.

The set of $\left(\bar{z}_{\mathrm{o}}, \underline{z}_{\mathrm{o}}\right)$ combinations which satisfy constraints (A.6), (A.7), and (A.8) is shown in Figure 2 as combinations in area $\mathrm{ABC}$. Based on the discussion of the preceding paragraph, the IFI's financial stability constraint must lie to the left of point A since (A.8) is not binding at the point where (A.6) and (A.7) are binding. 
Figure 1. Conditional Versus Unconditional Assistance Choices

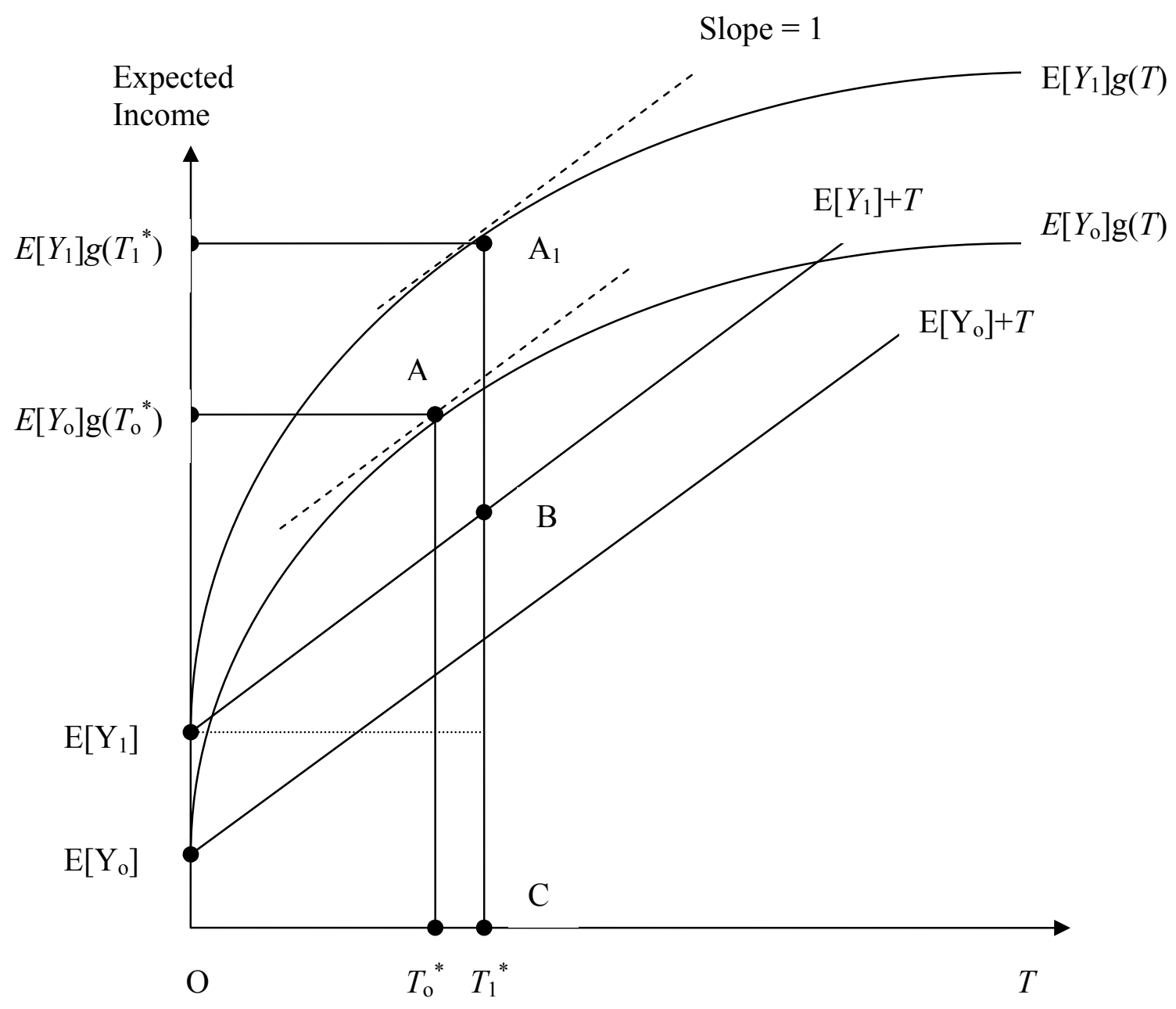


Figure 2. Repayment Constraint Set With Unconditional Assistance

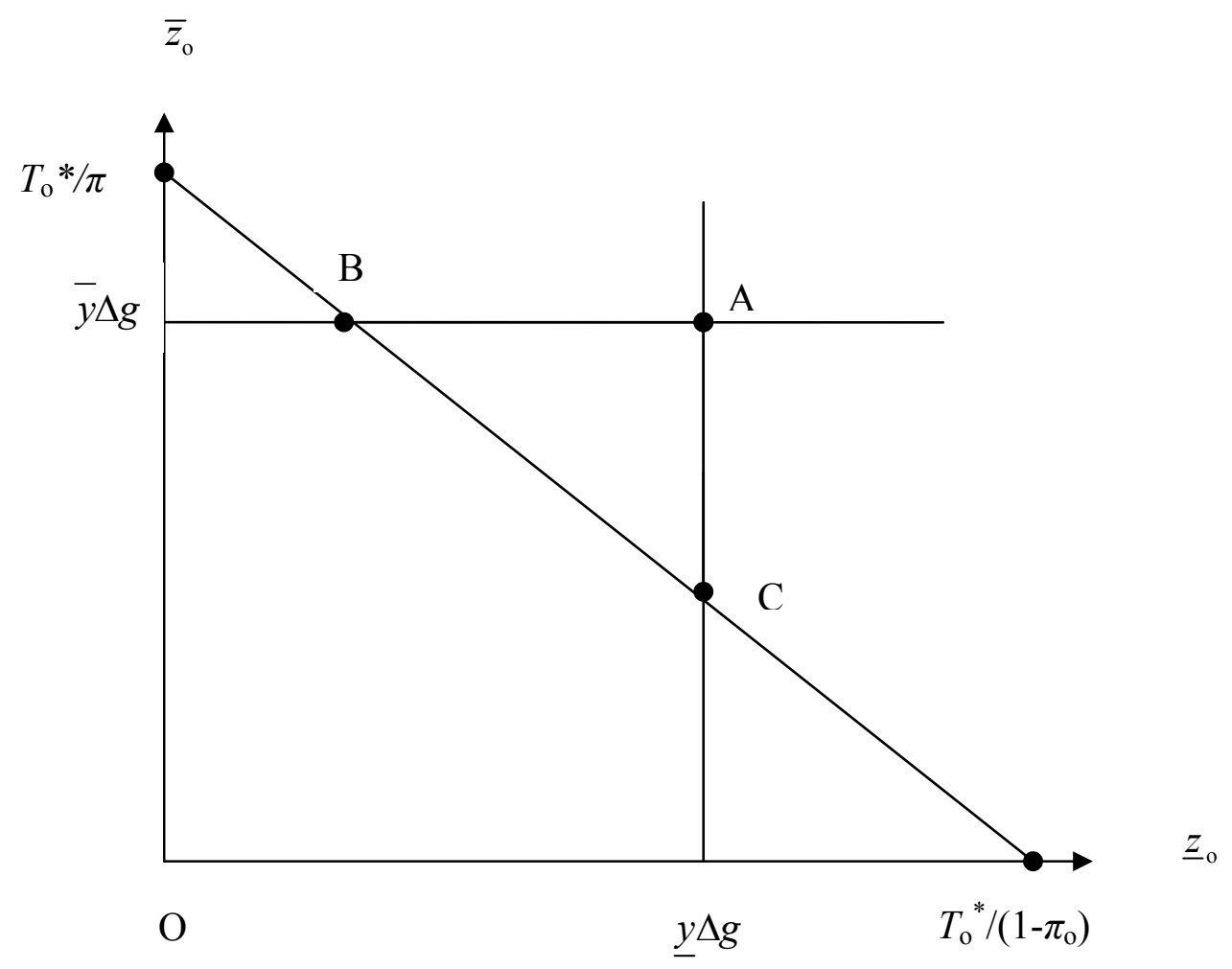




\section{REFERENCES}

Bhagwati, Jagdish N., 1980, “Lobbying and Welfare," Journal of Public Economics, Vol. 14 (December), pp. 355-63.

— 1982 , "Directly Unproductive, Profit Seeking (DUP) Activities," Journal of Political Economy, Vol. 90, No. 5, pp. 988-1002.

— Profit-Seeking (DUP) Lobbying Activities: Price Versus Quantity Distortions," Journal of International Economics, Vol. 13 (August), pp. 33-44.

Boughton, James M., and Alex Mourmouras, 2004, "Whose Programme Is It? Policy Ownership and Conditional Lending," in The IMF and Its Critics: Return of Global Financial Architecture, ed. by David Vines and Christopher L. Gilbert (Cambridge, U.K.: Cambridge University Press).

Dixit, Avinash, 2000, “IMF Programs as Incentive Mechanisms," mimeo, International Monetary Fund (June).

— , 2001, "Some Lessons from Transaction-Cost Politics for Less-Developed Countries", Olson Memorial Lecture delivered at the University of Maryland, October 26. Available via Internet: http://www/bsos.umd.edu/umccc/olson_memorial_lecture_series_schedule.htm

Dollar, David, and Jakob Svensson, 2000, "What Explains the Success or Failure of Structural Adjustment Programmes?” Economic Journal, Vol. 110 (October), pp. 894-917.

Drazen, Allan, 2002, "Conditionality and Ownership in IMF Lending: A Political Economy Approach,” Staff Papers, International Monetary Fund, Vol. 49, Special Issue, pp. 36-67.

Grossman, Gene M., and Elhanan Helpman, 1994, "Protection for Sale," American Economic Review, Vol. 84 (September), pp. 833-50.

Hillman, Arye L., 1982, "Declining Industries and Political-Support Protectionist Motives," American Economic Review, Vol. 72 (December), pp. 1180-87.

International Monetary Fund, 2000, "IMF Adopts Added Safeguards on Use of Its Resources," Public Information Notice No. 00/28 (April 4). Available via Internet: http://www.imf.org/external/np/sec/pn/2000/pn0028.htm

_ 2001, "Strengthening Country Ownership of Fund-Supported Programs" (December 5). Available via Internet: http://www.imf.org/external/np/pdr/cond/2001/eng/strength/120501.htm 
_ 2002a, "Guidelines on Conditionality" (September 25). Available via Internet: http://www.imf.org/external/np/pdr/cond/2002/eng/guid/092302.htm

_ 2002b, "Evaluation of Prolonged Use of IMF Resources," (Washington: Independent Evaluation Office).

— , 2004a, "IMF Approves Decisions Strengthening the Effectiveness of the Legal Framework for the Provision of Information to the Fund," Public Information Notice No. 04/10 (February 23). Available via Internet: http://www.imf.org/external/np/sec/pn/2004/pn0410.htm

— 2004b, "Signaling by the Fund — A Historical Review," (Washington: Policy Development and Review Department). Available via Internet: http://www.imf.org/external/np/pdr/signal/2004/071604.pdf

Ivanova, Anna, Wolfgang Mayer, Alex Mourmouras, and George Anayiotos, 2003, "What Determines the Implementation of IMF-Supported Programs?" IMF Working Paper 03/8 (Washington: International Monetary Fund).

Marchesi, Sylvia, and Jonathan P. Thomas, 1999, "IMF Conditionality as a Screening Device,” Economic Journal, Vol. 109 (March), pp. C111-25.

Mayer, Wolfgang, and Alex Mourmouras, 2005, "The Political Economy of IMF Conditionality: A Common Agency Model," Review of Development Economics (forthcoming).

Mussa, Michael, and Miguel Savastano, 1999, "The IMF Approach to Economic Stabilization,” IMF Working Paper 99/104 (Washington: International Monetary Fund).

Svensson, Jakob, 2003, "Why Conditional Aid Does Not Work and What Can Be Done About It?" Journal of Development Economics, Vol. 70, Issue 2, pp. 381-402.

Tirole, Jean, 2002, Financial Crises, Liquidity, and the International Monetary System (Princeton and Oxford: Princeton University Press). 